\title{
XXXIV. On the identity of columbium and tantalum
}

\section{William Hyde Wollaston M.D.Sec.R.S.}

To cite this article: William Hyde Wollaston M.D.Sec.R.S. (1810) XXXIV. On the identity of columbium and tantalum , Philosophical Magazine Series 1, 35:143, 201-205, DOI: 10.1080/14786441008563057

To link to this article: http://dx.doi.org/10.1080/14786441008563057

曲 Published online: 18 May 2009.

Submit your article to this journal $\pi$

LII Article views: 3

Q View related articles $\sqsubset$

4 Citing articles: 1 View citing articles 
every thing which may be presented in nature; and the art of advantageously applying the method, leads an expert eye to find the art of knowing how to dispense with it altogether.

[To be continued.]

XXXIV. On the Identity of Columbium and Tantalum. By Willaam Hyde Wollaston, M.D. Sec.R.S.*

W

ITHIN a short time after the discovery of columbium by $\mathrm{Mr}$. Hatchett in $1801 \mathrm{t}$, a metallic substance was also discovered in Sweden by M. Ekebergt, differing from every metal then known to him; and accordingly he described the properties by which it might be distinguished from those which it most nearly resembled. But although the Swedish metal has 'retained the name of Tantalum given to it by $\mathbf{M}$. Ekeberg, a reasunable degree of doubt has been entertained by chemists, whether these two authors had not in fact described the same substances; and it has been regretted that the discoverers themselves, who would have been most able to remove the uncertainty, had not had opportunities of comparing their respective minerals, or the products of their analyses.

As I have lately obtained small specimens of the two Swedish minerals tantalite and yttro tantalite, from which I could obtain tantalum, and was very desiross of comparing its properties with those of columbium, $\mathrm{Mr}$. Hatchett very obligingly furnished me with some oxide of the latter, which remained in his possession.

The resemblance was such in my first trials, as to induce me to endeavour to procure a further supply of columbium; and by application to the trustees of the British Museum, I was allowed to detach a few grains from the original specimen analysed by Mr. Hatchett.

Notwithstanding the quantity employed in my analyses was thus limited, I have, nevertheless, by proportionate cecnnomy of the materials, been enabled to render my experiments sufficiently numerous, and have found so many points of agreement in the modes by which each of these bodies can or cannot be dissolved or precipitated, as to prove very satisfactorily that these American and Swedish specimens in fact contain the same metal: and since the

* From Phil. Trans. 1809, Part II.

+ Phil. Trans. for 1802 .

Vetenkaps Academiens Handlingar. 1802, p, 68,-Joumal des Mines, rol. xii. p. 245. 


\section{On the Identity of Columbium and Tantalum.}

re-agents $I$ have employed are in the hands of every chemist, the properties which I shall enumerate are such as will be most useful in the practical examination of any other minerals in which this metal may be found to occur.

In appearance the columbite is so like tantalite, that it is cxireme! difficult to discern a difference that can be relied upon. The external surface, as well as the colour and lustre of the fracture, are precisely the same; but colu:abite breaks rather more easily by a blow, and the fracture of it is less uniform, appearing in some parts irregularly shattered; nevertheless, when the two are rubbed against each other, the hardness appears to be the same, and the colour of the scratch has the same tint of very dark brown.

By analysis also, these bodies are found to consist of the same ihree ingredients; a white oxide, combined with iron and manganese.

Either of these minerals, when reduced to powder, is very readily acted upon by potash ; but as the iron contained in them is not affected hy alkalies, it appeared better to add 2 small proportion of borax.

Five grains of columbite being mixed with 25 grains of carbonate of potash and ten grains of borax; were fused together for a few minutes, and found to be perfectly incoiporated. The colour was of a deep green, from the quantity of manganese present. The mass when cold could be softened with water, and a portion of the oxide could be so dissolved; but it seemed preferable to employ dilute muriatic acid, which, by dissolving all other ingredients excepting columbitum, left the oxide neariy white, by the removal of iron and manganese that had been combined with it.

The muriatic solution having been poured off and neutralized with carbonate of ammonia, the iron was then separated by succinate of ammonia; after which the manganese was precipitated by prussiate of potash.

The products thus obtained from five grains of columbite, after each bad been heated to redness, nere nearly,

White oxide........ grains

Oxide of iron ........

Oxide of manganese .... $\frac{1}{4}$;

but it cannot be supposed that proportions deduced from experiments made on so small a scale can be entirely depended upon, although the properties of bodies may be so discerned, nearly as well as when larger quantities are employed. 
An equal weight of tantalite taken from a specimen, of which the specitic gravity of $7 \cdot 8$, yielded, by the same treatment,

White oxide $\ldots \ldots \ldots \ldots+\frac{1}{2}$ grains.
Oxide of iron $\ldots \ldots \ldots \ldots \frac{1}{2}$
Oxide manganese $\ldots \ldots \ldots \frac{2}{10}$.

The white oxides obtained from each of these minerals are remarkable for their insolubility in the three common mineral acids, as both Mr. Hatchett and M. Ekeberg have observed.

In muriatic acid they cannot be said to be absolutely insolubie; but they are not sufficiently soluble for the purposes of analysis. luble.

In nirric acid they are also nearly, if not perfectly, inso-

In sulphuric acid, when eoncentrated and boiling, the oxide of columbium may be dissolved in small quantity, and $\mathrm{s}^{2}$ also may the oxide obtained from tantalite.

The proper solvent, as has been observed by Mr. Hatchett and by $M$. Ekeberg, is potash ; and as it is not required to be in its caustic state, I employed the crystallized carbonate of potash on account of its purity and uniformity. Of this sait about eight grains, seemed requisite to be fused with one of the oxide obtained from either of these minerals to render it soluble in water.

Soda also combines with the oxide, and may be said to dissolve it ; but a far larger proportion of this alkali is necessary, and a larger quantity of water. And although a solution may have been effected that is transparent while hot, it very soon becomes opaque in cooling, and finally almost the whole of the oxide subsides combined with a portion of the soda in a state nearly insoluble.

When a solution of the white oxide, obtained from either of these minerals, has been made, as above, with potash, the whole may be precipitated by the addition of an acid, and will not be redissolved by an excess of sulphuric acid, of nitric, of muriatic, succinic, or acetic acids.

But there is a further agreement in the properties of these two minerals, which appears above all others to establish their identity; for though they are both so nearly insoluble by any excess of the mineral acids, yet they are each completely dissolved by oxalic acid, by tartaric acid, or by citric acid; and the solution of each is subject to the same limitations; for if the precipitate has been dried, it is become intractable, and can scarcely be dissolved again till after a second fusion with potash. 


\section{On the Identity of Columbium and Tantalum.}

If to the alkaline solution of eirher of them there be added infusion of galls, prussiate of potash, or hydrosulphuret of potash, no precipitate occurs ; but when a sufficient quantity of acid has been added to neutralize the redundant alkali, the infusion of galls will then occasion an orange precipitate; but prussiate of potash causes no precipitate, nor does the bydrosulphuret precipitate the oxide, although the solution may become turbid from precipitation of sulphur by a redundant acid.

The characteristic precipitant of columbium is consequently the infusion of galls; but in the employment of this test certain precautions are necessary. For as an excess of potash may prevent the appearance of this precipitate, so also may a small excess of oxalic or tartaric acids prevent precipitation, or dissolve a precipitate already formed. A larger excess of citric acid seemed requisite for that purpose, and wonld also dissolve the gallat of columbium. In each case the precipitate may be made to appear by neutralizing the redundant acid; and for this purpose carbonate of ammonia should be employed : for although pure ammonia has no power of dissolving the oxide alone, yet the gallat seemed to be perfectly redissolved by that alkali.

When infusion of galls is poured upon the white oxide recently precipitated, and still moist, it combines readily, and forms the orange-coloured compound.

Prussiate of potash occasioned no change in an oxide that had been purified by a second fusion with potash ; but it appeared to dissolve a small portion of the oxide, as infusion of galls, poured into the clear liquor, occasioned a cloudy precipitate of an orange colour, though no such precipitate took place when the infusion was mixed with the same prussiate alone.

Hydrosulphuret of potash being added to the oxide, and heated upon it, impaired the whiteness of its appearance, and seemed to detect the remains of some impurity which had not yet been removed by other means; but no appearance indicated the formation of a sulphuret of columbium.

From a careful repetition of these experiments upon each of the oxides, I see no reason to cloubt of their perfect agreement in all their chemical properties; but there is nevertheless a very remarkable difference in the specific gravities of the two minerals from which they are extracted.

The specific gravity of columbite was ascertained by $\mathrm{Mr}$. Hatchett to be 5.918 ; that of tantalite was found by $M$. 
Ekeberg to be $7 \cdot 953$; and I have every reason to suppose their results correct, since a small fragment of the former appeared upon trial to be 5.87 , while a specitren of tantalite, weighed at the same time, was as much as $7 \cdot 8$. I should, however, observe, that the specific gravities of three other fragments borrowed for this purpose were not so high, that of one being $7 \cdot 65$, of another $7 \cdot 53$, and of 2 third so low as $7 \cdot 15$.

It is evident that no variation of mere proportion of the ingredients can account for an increase of specific gravity from $5 \cdot 918$ to $7 \cdot 953$, which are in the ratio of 3 to 4 ; for since columbite contains four fifths oxide, if the whole remaining one fifth part in weight of that oxide could be supposed added to the same bulk, without diminution of the quantities of iron and manganese, the specific gravity would not then exceed $7 \cdot 1$; and even if a weight equal to one third of the whole were thus added, without increase of bulk, still the aggregate would not quite equal the heaviest tantalite in specific gravity; but on the contrary, the quantity of white oxide in this specimen certainly does not amount to six sevenths, and probably is not more than five sixths of the whole mass.

The only chemical difference, by which this circumstance could be explained, would be the state of oxidation, which my experiments cannot appreciate; but it may also arise in part from actual cavities in the mass of columbite, and in part from the state or mode of aggregation.

XXXV. Description of a Method of fitting up in a portable Form The Electric Column lately invented by J. A. Dr Luc, Esq. Also an Account of several Experiments made with it. By B. M. Forster, Esq.

To Mr. Tilloch.

Sir, Having been informed that a row of galvanic plates had bcen consuructed without any fluid being interposed, and that it acted very sensibly on a gold-leaf electrometer, I formed one, of about wo hundred small circles of zinc, and the same number of blotting-paper and Dutch gold-leaf, the Dutch leaf being cemented on the paper with a solution of gum arabic; the blotting-paper was double, two pieces were gummed or pasted together before the Dutch leaf was put on. Through these circles, or plates, a silken string was passed for connecting them together. This small instru- 